\title{
CALCIFICATION OF THE LARYNGEAL AND TRACHEAL CARTILAGES ASSOCIATED WITH CONGENITAL STRIDOR IN AN INFANT
}

\author{
BY \\ SYLVIA NABARRO \\ From The Hospital for Sick Children, Great Ormond Street, London \\ (RECEIVED FOR PUBLICATION MAY 26, 1951)
}

Calcification of the laryngeal and tracheal cartilages is not seen before the fifteenth year except in the body and greater horns of the hyoid, where it is present from the fifth month of prenatal life (Caffey, 1950). A search of the literature has not disclosed any description of this condition occurring in infancy, nor has it ever been seen in this hospital where over 7,500 chest radiographs are taken

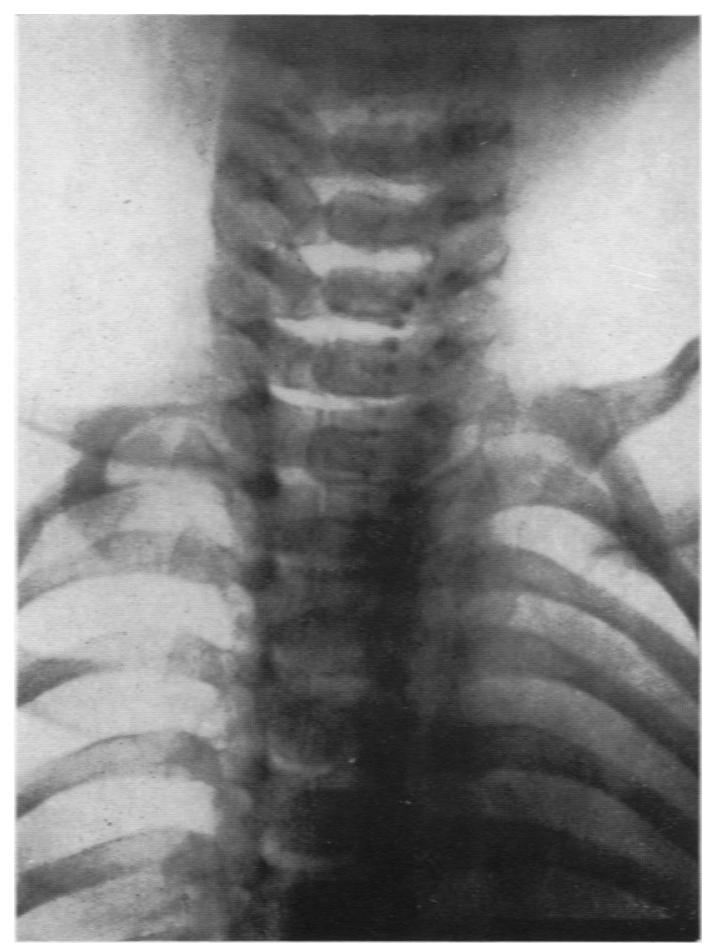

Fig. 1.-Antero-posterior radiograph showing the calcification. annually. For this reason the following case history was thought to be worth recording.

\section{Case Report}

The baby, a boy now aged 9 months, was born at full term by a normal delivery. He is the second child of healthy parents, and his sister, aged 21 months, is also well. There have been neither miscarriages nor stillbirths. He had a stridor at birth, and this has persisted

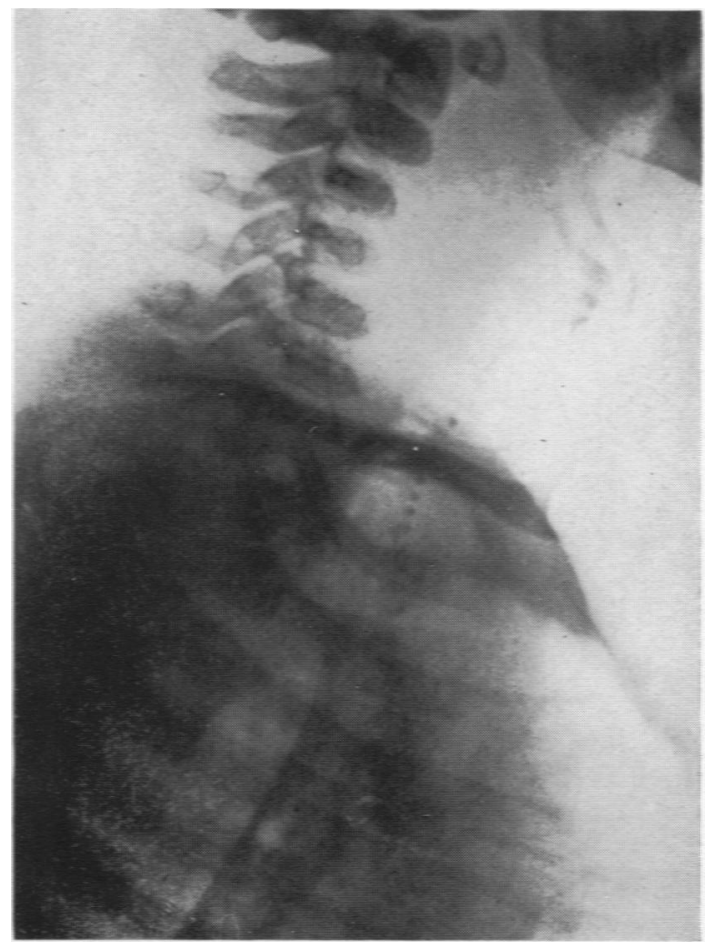

Fig. 2-A bateral radiograph of the same site. 
unchanged. He has never been cyanosed or distressed, but has had severe recurrent upper respiratory infections from the first few days of life. He has, however, thrived well and can sit and stand at nine months. He has received cod liver oil from birth, but never in excessive amounts.

On examination, he was found to be a well-nourished child with a marked inspiratory stridor. There were generalized coarse râles in the chest, and minimal rib recession. There were no other abnormal findings, and no undue rigidity of the larynx or trachea was felt. A radiograph of the larynx and trachea showed calcification of the anterior parts of the hyoid, thyroid, cricoid and tracheal cartilages.

Radiographs of the whole skeleton showed normal bone structure, and there were no calcium deposits in the kidneys or the cartilages of the ears and nose.

The parents and sister were also radiographed but were found to be normal.
The blood chemistry was investigated and the following figures obtained: serum calcium $9.0 \mathrm{mg} .{ }^{\circ}$; blood inorganic phosphorus $3.7 \mathrm{mg}$. ${ }_{0}^{\circ}$ : alkaline serum phosphatase 13.2 units (normal 10-20); plasma chlorides $606 \mathrm{mg}$. ${ }^{\circ}$ : plasma bicarbonate 58.6 vols. $\mathrm{CO}_{2}{ }^{\circ}$ : blood urea $23 \mathrm{mg}$. ${ }^{\circ}$.

Laryngoscopy was performed by Mr. J. Crooks, who found the larynx and trachea to be normal in size and elasticity. The former showed marked infantile characteristics.

It was possible, therefore, to exclude hypervitaminosis D or a general metabolic disorder, as a cause of the atopic calcification, but no alternative aetiology was suggested. There seemed to be no direct association between the calcification and the congenital stridor.

\section{Reference}

Caffey, J. (1950). ' Pediatric X-ray Diagnosis`. 2nd ed., p. 152. Chicago. 